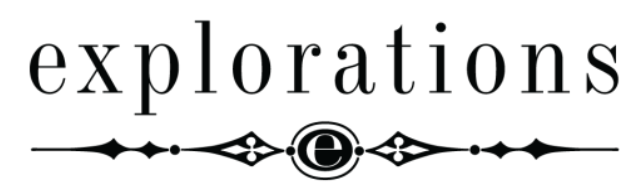

Explorations: A Journal of Language and Literature

\title{
REVIEW
}

\section{Lena Baunaz, Karen de Clerq, Liliane Haegeman, Eric Lander (eds.). 2018. Exploring Nanosyntax. Oxford: Oxford University Press.}

DOI: $10.25167 / \mathrm{EXP} 13.19 .7 .14$

Janusz Malak (University of Opole)

ORCID: 0000-0003-1507-7038

Exploring Nanosyntax edited by Baunaz et al. is a relatively recent item published in the series entitled Oxford Studies in Comparative Syntax. As the title of the series implies the material which makes the contents of the book under review should be useful in the contrastive analysis of languages. Nanosyntax appears to be an alternative to Chomsky's $(1995,2000,2001)$ minimalist program as regards syntactic theorising. Certain elements of the minimalist program have been adopted in nanosyntax, e.g. two levels of representation, i.e. LF and PF, as well as the workspace corresponding to narrow syntax in the minimalist program where syntactic operations take place. What the two approaches to syntactic structures differ in is what takes place in the above mentioned workspace. In this respect nanosyntax is more of representational character in contrast to the derivational guise of the minimalist program. The source of this difference lies in the adoption of the cartographic approach as presented in Rizzi (1997) and Cinque (1999). The aim of this approach is to identify the set of syntactic heads which are exponents of features, due to the assumption that each head carries one feature (one head one feature principle), as well as the hierarchical organisation of these heads. Both the set of heads and their hierarchical organisation are considered to be universal and the crosslinguistic variation is attributed to the ways in which these structures are realised as well as the type of the constituent displacement allowed by these structure.

Another difference between the minimalist program and nanosyntax is the way in which the lexical items feeding syntax are treated in the two approaches. In contrast to the minimalist program, where lexical items are analysed as aggregates of feature of three types and are merged in the narrow syntax in the initial stages of the syntactic derivation, in nanosyntax words are inserted in the final stages of the syntactic processes as the means of lexicalisation or spell-out (Vocabulary Insertion). Nanosyntax is also committed to the idea that syntax accounts not only for the structure of sentences but also for the structure of words. In other words, morphemes, which are lexicalisations of feature bundles, seem to be treated on the same footing as other syntactic objects, the idea shared, to a certain extent, with Distributed Morphology, as presented in Halle and Marantz (1993).

Explorations: A Journal of Language and Literature, 7 (2019), pp. 137-140 
Whether or not such a combination of certain elements of the architecture of the minimalist program, the syntactic cartography, and certain elements of Distributed Morphology can produce an explanatorily adequate approach to language contrast on the synchronic or diachronic plane is at present hard to answer. Exploring Nanosyntax must be surely treated as an attempt to answer this question.

The book under review consists of contributions by twelve authors specialising in nanosyntax, whose names along with brief information concerning the contributors are listed in the initial part of the book following 'Preface'. The twelve chapters are grouped in three parts whose titles are, respectively, 'Background', 'Empirical Investigations', and 'Theoretical Explorations'. At the end of the book one finds Glossary containing concepts used in nanosyntactic analysis. The presentation of the foundations of nanosyntax is the subject matter of three chapters in the first part which offer a comprehensive presentation of the theoretical and methodological assumptions on which nanosyntax is based. This part is very helpful in reading the contributions in parts two and three. The contributions in part two are examples of the implementation the nanosyntactic methodology in tackling concrete linguistic problems coming from various language. In this part one finds a squib by Michal Stark on Kim's Korean question particles treated as pronouns, an article by Eric Landner and Liliane Haegeman on syncretism and containment in spatial demonstrative expressions deals with linguistic material from forty languages which are not genetically related to one another, a contribution by Lena Baunaz presenting a decompositional analysis of complementisers in French, Modern Greek, Serbo-Croatian, and Bulgarian, an article by Karen de Clercq on the syncretism and morphosyntax of negation, and, finally an account of the problem connected with the interpretation of Russian verbal prefixes form the nanosyntactic prespective by Inna Tolskaya which closes this part.

Part three contains four contributions concerned with the issues which still remain unresolved at the present stage of the development of nanosyntax. The chapter by Michal Stark is mainly concerned with prefixes and suffixes. The latter are analysed as a part of the main spine, a term which is not satisfactorily defined and which seems to roughly correspond to phrase markers in the Government and Binding Theory, in the primary derivation while the former formants are the result of the secondary derivation and, being the last resort operation, are placed in the main spine in complex specifiers. The problems connected with the word order in the nanosyntactic perspective in three varieties of Spanish, i.e. European Spanish, Venezuelan Spanish, and Dominican Republic Spanish, are the contents of the contribution by Antonio Fabregas. In this chapter the distribution of preverbal nominal expressions functioning as subject in interrogative clauses is analysed in the above mentioned three varieties of Spanish. The question of the syncretism characterising personal pronoun paradigms is the contents of the chapter by Guido Vanden Wyngeard. In this chapter the validity of the *ABA diagnostic is examined which is based on the assumption that non-contiguous syncretisms should, in principle, be excluded. Two approaches are adopted to achieve this objective, i.e. the approach based on the idea of pointers postulated in Caha and Pantcheva (2012) and the revised version of Superset Principle proposed by Caha (2009). The two approaches adopted for the evaluation of validity of the $* \mathrm{ABA}$ diagnostic in the case of pronominal forms produce different results.

The final chapter in the book under review entitled 'Functional Sequence Zones and Slavic L $>\mathrm{T}>\mathrm{N}$ Participles' by Lucie Taraldsen Medova and Bartosz Wiland is mainly 
concerned with distinct 'zones' of functional features in participial forms in Polish and Czech. It is argued in this contribution that the same functional feature zone (fseq zone) is the result of competing on the part of two elements with each other for insertion in this zone. Elements that co-occur together belong to different fseq zones. Three zones are identified on the basis of participial forms and suffixes in Polish and Czech, i.e. root, theme, and participle. Each zone is characterised by its own complex internal structure. Adopting this approach the authors of this chapters are able to offer an interesting solution to the problem connected with the formation of passive participial forms ending in $l$ (adjectival L-passives, e.g. zmar-t-y/zmrz-l-a) on the basis of unaccusative verb roots, the property which seems to be unavailable in the case of unergative verb roots in the two languages.

Reading the chapters in the second and third parts of Exploring Nanosyntax one cannot resist an impression that the main objective of nanosyntactic analysis is actually word, especially those parts of this linguistic unit which carry multiple syntactic information known in traditional accounts as cumulative exponents. Of the twelve contributions in this book only one is of genuinely syntactic character, i.e. the one on the distribution of the nominal expression functioning as subject in interrogative clauses by Antonio Fabregas. It can be said that the problems presented in this book and the way in which they are dealt with satisfy Chomsky's observational and descriptive level of adequacy. However, it is still early to answer the question whether the explanatory level of adequacy is achieved through nanosyntactic theorising. Anyway, the book edited by Baunaz et al. entitled Exploring Nanosyntax is recommended to anyone interested in exploring the boundary between inflection and syntax not necessarily from the generative perspective.

\section{REFERENCES}

Caha, Pavel. 2009. "The Nanosyntax of Case". PhD diss., University of Tromsø.

Caha, Pavel, and Marina Pantcheva. 2012. "Contiguity beyond Linearization: Modelling Cross-Dimensional Syncretism". Paper presented at Workshop on Rerpresentation and selection of exponent. Available athttp://cms.unge.ch/lettres/linguistique/ seminaire/media/220/Caha\%Pantcheva\%20231012.pdf.

Chomsky, Noam. 1995. The Minimalist Program. Cambridge, MA: The MIT Press.

Chomsky, Noam. 2000. "Minimalist Inquiries: The Framework". In Step by Step: Essays on Minimalist Syntax in Honor of Howard Lasnik, edited by Roger Martin, David Michaels, and Juan Uriagereka, 89-157. Cambridge, MA: The MIT Press.

Chomsky, Noam. 2001. "Derivation by Phase". In Ken Hale: A Life in Language, edited by Michael Kenstowicz, 1-52. Cambridge, MA: Tthe MIT Press.

Cinque, Gugliemo. 1999. Adverbs and Inflectional Head. Oxford: Oxford University Press.

Halle, Morris, and Alec Marantz. 1993. "Distributed Morphology and the Pieces of Inflection". In The view from Building 20: Essays in Linguistics in Honor of Sylvain Bromberger, edited by Kenneth Hale, and Samuel Jay Keyser, 111-176. Cambridge, MA: The MIT Press. 
Rizzi, Luigi. 1997. "The Fine Structure of the Left Periphery". In Elements of Grammar, edited by Liliane Haegeman, 281-337. Dordrecht: Kluwer.

This work is licensed under the Creative Commons Attribution 3.0 Unported License.

http://creativecommons.org/licenses/by/3.0/

AUTHOR'S BIO: Janusz Malak is a senior lecturer at University of Opole. His main research interests are the following: generative grammar (minimalist program), contrastive grammar, diachronic linguistics, philosophy of language.

E-MAIL: jmalak@uni.opole.pl 